\title{
Abordagens e Teorias de Aprendizagem Propostos pelos Projetos dos Cursos de Pedagogia a Distância para o Desenvolvimento de Tecnologias Educacionais
}

Approaches and Theories of Learning Proposed

by the Projects of Pedagogy Distance Education Course for the Development of Educational Technologies

${ }^{1}$ Programa de Pós-Graduação em Educação Matemática e Tecnológica da UFPE, Avenida Acadêmico Hélio Ramos s/n, Cidade Universitária Recife - PE - Brasil.

amanda@didatics.com.br

2 Programa de Pós-Graduação em Educação Matemática e Tecnológica da UFPE, Avenida Acadêmico Hélio Ramos s/n, Cidade Universitária Recife - PE - Brasil.

anabeatrizgpc@gmail.com
Amanda Amorim Costa e Silva *1, Ana Beatriz Gomes Carvalho²

\section{Resumo}

O presente trabalho traz os resultados de uma pesquisa que procurou identificar de quais abordagens e teorias de aprendizagem provêm os princípios didático-pedagógicos que os Projetos Pedagógicos de Curso (PPCs) dos cursos de Pedagogia a distância oferecidos por universidades federais da Região Nordeste propõem para o planejamento e desenvolvimento de suas tecnologias educacionais (ambientes, materiais e atividades). Após a revisão de literatura sobre abordagens e teorias de aprendizagem, seguida das análises documental e de conteúdo dos PPCs, identificamos que preponderam princípios escolanovistas, construtivistas e socioconstrutivistas. Contudo: a) a forma de operacionalização de tais princípios no planejamento e desenvolvimento dos ambientes, materiais e atividades é pouco objetiva; e b) os processos de avaliação da aprendizagem (e instrumentos utilizados) não são descritos ou o são de forma imprecisa. Tais achados sugerem que os PPCs, documentação balizadora dos cursos, não são utilizados como referência para o planejamento e o desenvolvimento das tecnologias educacionais empregadas nos cursos investigados.

Palavras-chave: Educação a distância, Pedagogia, Teorias de aprendizagem, Tecnologias educacionais, Projeto pedagógico de curso. 


\section{Approaches and Theories of Learning Proposed by the Projects of Pedagogy Distance Education Course for the Development of Educational Technologies}

\section{Abstract}

This paper presents the results of a study that aimed to identify from which learning approaches and theories come the didactic and pedagogical principles that the Course's Pedagogical Project o (PPCS) of Pedagogy distance courses offered by federal universities in the Northeast region propose to design and develop their educational technologies (environments, materials and activities). After a literature review of approaches and learning theories, followed by the documentary and content analysis of PPCS, we identified that the prevail principles come from New School, Constructivist and Socioconstrutivism. However: a) the documents are not objectives on how to operationalize these principles in designing and developing environments, materials and activities, and; $b$ ) the learning evaluation processes (and instruments) are not described or are inaccurate. These findings suggest that the PPCs, the basic documentation of the courses, are not used as references for designing and developing the educational technologies used in the investigated courses.

Keywords: Distance education, Pedagogy, Learning theories, Educational technologies, Course projects.

\section{Introdução}

O Projeto Pedagógico de Curso - PPC é um documento oficial que, entre outras coisas, identifica a proposta didático-pedagógica que orienta determinado curso superior, ou seja, como os processos de ensino-aprendizagem (e tecnologias relacionadas) são compreendidos, fundamentados. Por ser o documento base de qualquer curso de graduação, presencial ou a distância, o PPC norteia (ou deveria nortear) o planejamento (design) e o desenvolvimento das tecnologias educacionais empregadas no curso, entendendo por tecnologia educacional todos os recursos e processos aplicados às práticas de ensino-aprendizagem.

Compreendendo a necessidade de investigarmos os princípios subjacentes ao planejamento de tais tecnologias, o presente trabalho, parte integrante de uma pesquisa maior, financiada pela Coordenação de Aperfeiçoamento de Pessoal de Nível Superior (CAPES), que culminou em uma dissertação de mestrado defendida e aprovada em fevereiro de 2016, sintetiza os achados de uma análise que procurou identificar quais abordagens e teorias de aprendizagem estão presentes nos textos dos PPCs dos cursos de Pedagogia a distância oferecidos pelas universidades federais da região Nordeste. Nosso objetivo era precisamente o de identificar os princípios didático-pedagógicos propostos pelos documentos para o planejamento da tecnologia educacional (ambientes virtuais, materiais didáticos e atividades) empregada nos cursos.

Nos tópicos seguintes, apresentaremos resumidamente as principais características de um Projeto Pedagógico de Curso, sintetizaremos algumas das abordagens e teorias de aprendizagem cujos princípios didático-pedagógicos pretendíamos identificar nos PPCs, descreveremos rapidamente a metodologia adotada em nossa investigação e, por fim, apresentaremos e discutiremos os dados encontrados. 


\section{A natureza do Projeto Pedagógico de Curso - PPC}

O PPC deve estar em sinergia com outros dois documentos fundamentais em qualquer instituição de ensino superior, o Projeto Pedagógico Institucional - PPI e o Projeto de Desenvolvimento Institucional - PDI. Outros documentos que precisam ser considerados durante a produção dos PPCs são as Diretrizes Curriculares Nacionais -DCN para os cursos de graduação, que são estabelecidas pelo Ministério da Educação - MEC. Cada curso tem sua DCN. Assim, é de se esperar que o PPC identifique as metas, a estrutura organizacional e as orientações operacionais que nortearão a prática pedagógica do curso em questão. É importante que estejam detalhadas a matriz curricular, as ementas e bibliografias das disciplinas e o perfil profissiográfico (conjunto de habilidades cognitivas, conhecimentos técnicos e atitudinais) do egresso (Simões, 2012).

Obrigatoriamente, devem estar expressas todas as cargas horárias das atividades didáticas, bem como da integralização do curso. O documento ainda deve dar conhecimento sobre as práticas avaliativas, sejam elas relacionadas à avaliação das práticas de ensino, sejam relacionadas à avaliação da aprendizagem. Devem estar descritos também os recursos humanos disponíveis para o curso, assim como os recursos materiais ou infraestrutura (própria e de terceiros) que a instituição utilizará.

Os compromissos didático-pedagógicos abraçados pelo curso, ou seja, as abordagens e/ou teorias de aprendizagem que balizam a prática pedagógica dos professores, também são um item importante do PPC. É preciso sinalizar o que fundamenta teórica e metodologicamente os processos de ensino-aprendizagem empregados e como tais princípios são operacionalizados, ou seja, como são materializados em tecnologias (artefatos e processos) educacionais.

\section{A abordagem escolanovista quanto à aprendizagem}

Os sistemas de ensino ocidentais foram profundamente impactados por um conjunto então emergente de propostas pedagógicas durante as últimas décadas do século XIX e as primeiras do século XX. Foram muitos os movimentos orientados por tais pedagogias, sendo a Escola Nova ou Ativa, capitaneada pelo filósofo americano John Dewey (1859-1952), provavelmente a mais influente dessas correntes, daí o uso do termo Escolanovismo na literatura educacional para nos referirmos tanto ao conjunto de ideias e práticas da própria Escola Nova quanto ao de outras pedagogias afins, como a Escola do Trabalho alemã e as propostas de pensadores independentes.

O ideário pedagógico escolanovista defende um processo de ensino-aprendizagem centrado na atividade do estudante, como atividades de investigação que tivessem como ponto de partida os interesses naturais dos estudantes, trabalhos com projetos, o uso de oficinas etc. (Racy, 2010). Para o Escolanovismo, a aprendizagem oferecida pelas instituições de ensino deve estar fortemente vinculada à realidade dos estudantes. É rejeitada a suposição de que a escola prepara para "a vida", como se a vida fosse algo a ser construído mais à frente. No âmbito do Escolanovismo, a escola prepara "na vida", por isso estabelece relação indissociável com a realidade individual e coletiva daqueles que aprendem (Ghiraldelli Júnior, 2006). No contexto da formação profissional, a abordagem escolanovista implica tirar proveito da experiência profissional do formando durante o processo formativo, seja para usar a realidade profissional como ponto de partida da formação, seja para promover a integração entre a teoria e a prática baseada na investigação da própria vivência.

Tamanha ênfase em atividades práticas e aprendizagens situadas em contextos reais põe em relevo a preocupação do Escolanovismo quanto à importância dos conhecimentos prévios para a promoção de aprendizagens bem-sucedidas e para a significância dos contextos nos quais tais 
aprendizagens devem acontecer. Quanto mais o estudante conseguir perceber relação entre os conhecimentos já adquiridos, a experiência vivida e aquilo que precisa ser adquirido por novas experiências, mais fácil seria o processo de aprendizagem (Racy, 2010).

É característica do Escolanovismo a rejeição ao livro e à figura de autoridade do professor. O autogoverno deveria ser incentivado nos estudantes por meio da vivência, da experimentação própria, da investigação em busca da verdade; logo, livros e professores seriam recursos de segunda importância (Piletti\&Pilleti, 2012).Entre as principais heranças deixadas pelo Escolanovismo em nosso sistema de ensino podemos citar as diversas abordagens de ensino orientadas à solução de problemas, como o método de projetos de William Kilpatrick (1871-1954). Kilpatrick propôs em 1918 o método, que consiste basicamente em engajar os estudantes em um projeto de investigação concebido e levado a cabo pelos próprios estudantes, sendo o professor um assessor ao longo do trabalho. Durante a execução do projeto, cabe aos estudantes identificar o problema, coletar e sistematizar a informação, cooperar com os colegas e chegar à solução (Piletti\&Piletti, 2012; Veiga, 2007).

O estudo do meio (atividades de ensino apoiadas em excursões e explorações de ambientes como museus, parques, jardins etc.), o ensino com pesquisa (aprendizagem baseada em investigação), o ensino contextualizado (no qual conteúdos são trabalhados em contextos nos quais ganham significado e aplicabilidade) e a aprendizagem situada (na qual são vivenciadas situações reais ou utilizadas simulações) também são abordagens fortemente ancoradas na aprendizagem experimental escolanovista. Mesmo ideias aparentemente recentes, como a defesa do "aprender a aprender", já faziam parte vocabulário escolanovista. "Aprender a aprender" era um dos lemas mais defendidos por Dewey (Ghiraldelli Júnior, 2006).

\section{A teoria piagetiana}

Chegou ao Brasil, nos anos 1980, o Construtivismo de Jean Piaget (1896-1980), também conhecido como Epistemologia Genética e Construtivismo Cognitivo. Piaget acreditava que mais importante do que ensinar (numa perspectiva de transmissão de conhecimentos) é oferecer aos estudantes materiais e situações de aprendizagem que os desafiem com problemas cuja solução demande engajamento, investigação. Tais situações devem ser encadeadas umas às outras de modo que o professor estabeleça um percurso de aprendizagem no qual o estudante possa progredir com liberdade, inclusive a liberdade para errar e aprender com o erro (Lerner, 2002). Percebe-se que, na ótica piagetiana, o professor é fundamentalmente um incentivador, estimulador e organizador das situações de aprendizagem.

O conflito sociocognitivo é também um dos princípios defendidos por Piaget para a educação. O conflito ocorre quando o estudante se depara com pontos de vista diferentes do seu sobre um mesmo fenômeno. Propor trabalhos em grupo nos quais ideias e explicações sobre fenômenos precisem ser negociadas obriga os estudantes a organizar seus pontos de vista em relação aos demais, contrastando-os e articulando-os; isso leva a uma compreensão mais aprofundada das questões em estudo e ao amadurecimento intelectual, mesmo quando nenhum dos estudantes tem a resposta certa (Richmond, 1981; Lerner, 2002).

Central, na teoria piagetiana, é o conceito de equilibração majorante, processo pelo qual procuramos manter o equilíbrio com o meio físico e social. Se determinado fator compromete tal estado de equilíbrio, tentamos manipular o fator desequilibrante ou nos adaptamos a ele para que um novo estado de equilíbrio possa ser alcançado. Dois subprocessos irmãos constituem o processo de equilibração: assimilação e acomodação. A assimilação se dá quando um sujeito se depara com um evento que é passível de ser compreendido com o repertório de esquemas (conhecimentos, habilidades e atitudes) que ele já possui. Este é o primeiro passo que empreendemos quando nos deparamos com qualquer situação nova: tentamos interpretá-la à luz do que já sabemos sobre o mundo. Quando o elemento de novidade contido na situação não pode ser satisfatoriamente compreendido por nosso repertório de esquemas, é necessária a 
acomodação, ou seja, a reformulação dessa estrutura cognitiva preexistente pela construção de um novo esquema, muitas vezes a partir de um anterior (Ormrod, 2012; Pilleti\&Rossato, 2012; Richmond, 1981).

O conceito de equilibração majorante tem consequências importantes em uma pedagogia apoiada em princípios piagetianos. Por um lado, é importante que toda situação de aprendizagem parta de uma situação que seja familiar ao sujeito, ou seja, que tire proveito dos esquemas ou conhecimentos prévios que ele já possui sobre o tema em estudo. De outro lado, uma situação completamente familiar não produzirá qualquer aprendizagem, por isso é necessário que haja um fator desequilibrante, um dado que o estudante não consiga interpretar adequadamente a partir do que já sabe, e que, portanto, demande novas aprendizagens (Richmond, 1981).

O estímulo às atividades práticas é um princípio integrante das propostas educacionais inspiradas na teoria de Piaget. Ele considerava que atividades realizadas em laboratórios, oficinas, cozinhas experimentais e outras situações que simulem contextos de uso real do conhecimento facultam ao estudante a oportunidade de relacionar conceitos abstratos ao meio físico concreto, por isso a aprendizagem por descoberta é uma prática absolutamente incentivada pelas propostas pedagógicas baseadas na teoria piagetiana. Tendo como ponto de partida um problema instigante, os estudantes devem conceber e conduzir atividades de pesquisa que visem à busca por uma explicação/solução. Nesse sentido, há grande afinidade entre a abordagem escolanovista da aprendizagem baseada em solução de problemas e em projetos de pesquisa e aprendizagem por descoberta piagetiana (Ormrod, 2012).

\section{O Socioconstrutivismo}

A teoria do pesquisador russo Lev Semionovitch Vygotsky (1896-1934), principal representante da Psicologia Histórico-Cultural, é amplamente conhecida como Socioconstrutivismo. Para Vygotsky, o homem, esse ser biológico, torna-se gradualmente também um ser psicossocial graças aos processos de socialização dos quais toma parte e que promovem a internalização das práticas sociais vigentes em seu grupo social de referência, entre elas o uso da linguagem (Pilleti\&Rossato, 2012; Oliveira, 2002; Ormrod, 2012). Muito mais do que ações reflexas (como sugar o seio da mãe), automatizadas (como direcionarmos a vista em direção à fonte de um som repentino) e a capacidade de realizarmos associações simples (como evitar tocar em uma agulha após um evento doloroso com o objeto), somos capazes de processos psicológicos superiores. Conseguimos pensar sobre pessoas e objetos ausentes, imaginar situações ainda não vivenciadas e planejar a vida futura.

Vygotsky afirma que existem dois tipos de instrumentos: a) instrumentos mais simples, tangíveis, utilizados como recurso para modificar materialmente o mundo; b) instrumentos mais complexos, simbólicos, utilizados em um tipo de atividade que modifica aquele que o utiliza, embora seus efeitos também repercutam no mundo material. Este segundo tipo de instrumento é adquirido por meio de um processo lento e que demanda interação social. De início, o uso de signos e estratégias como ferramentas cognitivas precisa de suporte material, como o uso dos dedos das mãos ou de rabiscos em uma parede para representar quantidades. Nossa memória e nosso raciocínio precisam de toda sorte de elementos externos. A internalização desses recursos que representam o real ocorrerá apenas ao longo do tempo e de sucessivas interações sociais. É o que Vygotsky chama de Lei da Dupla Formação. Todo conhecimento precisa ser adquirido duas vezes: uma como prática social, outra como processo psicológico (Oliveira, 2002; Ormrod, 2012).

No que diz respeito ao papel da instituição escolar, ele entende ser função do mestre mediar a relação que os estudantes devem desenvolver com o conhecimento científico, de modo que a apropriação desse saber fomente a curiosidade e o desejo por novos saberes e ajude na formação e no aperfeiçoamento das funções psicológicas superiores, como a imaginação, o foco da atenção, as capacidades linguísticas etc. No período escolar, técnicas e tecnologias muito específicas estarão disponíveis ao estudante para que 
ele possa apropriar-se delas e aplicá-las como recursos de apoio aos processos intelectuais, refinando-os (Piletti\&Rossato, 2012). Na perspectiva de Vygotsky, o planejamento adequado das atividades escolares deve prever a interação (mediação) social, de modo a favorecer a aquisição das capacidades e saberes que estão no limiar da aprendizagem já consolidada, ou seja, o desenvolvimento das aprendizagens que, com alguma ajuda, podem deixar de ser aprendizagens potenciais ou emergentes e se tornar aprendizagens efetivas. Todos nós temos nossos repertórios de aprendizagens consolidadas, e no limiar desse repertório encontram-se as aprendizagens potenciais, que constituem a Zona de Desenvolvimento Proximal - ZDP. Para Vygotsky, é sobre essas aprendizagens emergentes que o processo pedagógico deve incidir (Piletti\&Rossato, 2012; Pritchard\&Woolard, 2010; Oliveira, 2002).

\section{Metodologia}

Tendo como objetivo identificar quais teorias e abordagens de aprendizagem têm seus princípios presentes nos textos dos PPCs dos cursos-alvo ${ }^{1}$, realizamos: a) a revisão da literatura pertinente (parte dela descrita nos tópicos anteriores); b) a análise documental dos PPCs; e c) a análise de conteúdo do material selecionado durante a análise documental.

A revisão de literatura teve por finalidade identificar os princípios didático-pedagógicos que cada paradigma de aprendizagem propõe para o desenvolvimento de ambientes de aprendizagem, materiais didáticos e atividades.Foram selecionadas diversas obras sobre o Escolanovismo, o Behaviorismo, o Cognitivismo, o Construtivismo piagetiano, o Socioconstrutivismo e o Conectivismo, de modo a sintetizar em nosso referencial teórico as principais diretrizes provenientes de tais abordagens para a aprendizagem escolar/acadêmica. Tais princípios foram organizados em uma matriz de categorias e subcategorias que serviram de base para as análises documental e de conteúdo que seriam realizadas posteriormente. Para nomear as categorias de análise, utilizamos os nomes das próprias abordagens (Escolanovismo, Behaviorismo etc.); as subcategorias de análise são os princípios didático-pedagógicos provenientes de cada abordagem.

A seguir reproduzimos a citada matriz, ocultando as categorias e subcategorias que não são pertinentes ao escopo deste artigo.

1 A pesquisa completa investigou também se os princípios citados são utilizados no desenvolvimento e na aplicação das tecnologias educacionais planejadas para os cursos. Contudo, considerando o melhor aproveitamento do espaço disponível para relatar a pesquisa, este artigo trata apenas da primeira parte de nosso trabalho: a análise dos PPCs dos cursos-alvo. 
Quadro 1 - Matriz de categoria e subcategorias de análise

\begin{tabular}{|c|c|}
\hline Categorias & Subcategorias \\
\hline \multirow{9}{*}{ Escolanovismo } & Pouco recurso ao texto \\
\hline & Materiais devem poder ser manipulados e utilizados em atividades práticas \\
\hline & $\begin{array}{l}\text { Materiais devem replicar instrumentos utilizados em contextos reais de traba- } \\
\text { lho }\end{array}$ \\
\hline & Ambientes devem despertar a curiosidade e a iniciativa \\
\hline & Ambientes devem simular o mundo real \\
\hline & Atividades devem articular teoria e prática com foco na vivência \\
\hline & $\begin{array}{l}\text { Atividades devem tirar proveito pedagógico dos conhecimentos prévios dos } \\
\text { estudantes }\end{array}$ \\
\hline & Foco em solução de problemas e aprendizagens por descoberta \\
\hline & $\begin{array}{l}\text { Os contextos das atividades devem ser significativos, de preferência em am- } \\
\text { bientes reais ou realistas }\end{array}$ \\
\hline \multirow{5}{*}{$\begin{array}{l}\text { Construtivismo } \\
\text { piagetiano }\end{array}$} & $\begin{array}{l}\text { Materiais devem oferecer informações partindo do que é mais familiar para o } \\
\text { que é menos familiar }\end{array}$ \\
\hline & Toda informação nova deve ser apresentada de forma desafiadora \\
\hline & $\begin{array}{l}\text { Materiais devem incitar a exploração do ambiente físico e social, despertando } \\
\text { a iniciativa e a curiosidade do estudante }\end{array}$ \\
\hline & Ambientes devem favorecer a interação social e a troca de ideias \\
\hline & $\begin{array}{l}\text { Atividades devem promover o conflito entre o que já se sabe e o que ainda } \\
\text { precisa ser aprendido, de maneira que o estudante sinta-se desafiado a rees- } \\
\text { truturar esquemas prévios }\end{array}$ \\
\hline \multirow{3}{*}{ Socioconstrutivismo } & $\begin{array}{l}\text { Materiais devem considerar o conhecimento prévio do aluno (aprendizagem } \\
\text { já consolidada), mas fazê-lo avançar rumo às aprendizagens que estão em } \\
\text { processo de consolidação }\end{array}$ \\
\hline & $\begin{array}{l}\text { Ambientes de estudo devem favorecer a interação social e o trabalho colabo- } \\
\text { rativo e cooperativo }\end{array}$ \\
\hline & $\begin{array}{l}\text { Atividades devem prever a mediação do professor e/ou de colegas mais } \\
\text { experientes }\end{array}$ \\
\hline
\end{tabular}

Fonte: Costa e Silva (2016, p. 165).

Concluída a revisão de literatura e identificadas as categorias e subcategorias de análise, teve início a análise documental, com o objetivo de identificar as partes relevantes para o nosso trabalho na documentação disponível. Nas palavras de Gil (2008, p. 147),

há dados que, embora referentes a pessoas, são obtidos de maneira indireta, que tomam a forma de documentos, como livros, jornais, papéis oficiais, registros estatísticos, fotos, discos, filmes e vídeos, que são obtidos de maneira indireta. Essas fontes documentais são capazes de proporcionar ao pesquisador dados em quantidade e qualidade suficiente para evitar a perda de tempo e o constrangimento que caracterizam muitas das pesquisas em que os dados são obtidos diretamente das pessoas. Sem contar que em muitos casos só se torna possível realizar uma investigação social por meio de documentos. 
De fato, só através da análise dos documentos oficiais seria possível identificar os compromissos didático-pedagógicos abraçados pelos cursos e os princípios subjacentes a tais compromissos, ou seja, os princípios propostos para o planejamento e o desenvolvimento das tecnologias (ambientes, materiais e atividades) empregadas nos cursos de Pedagogia.

Nessa etapa da pesquisa, foram selecionados os capítulos e subcapítulos dos PPCs que faziam referências às categorias e subcategorias de análise existentes em nossa matriz. O material não relacionado foi descartado. Para realizar essa seleção, não utilizamos software de análise. Os cinco PPCsem formato PDF foram lidos integralmente e tiveram os capítulos e subcapítulos pertinentes separados do material irrelevante.

Selecionado o material pertinente, iniciamos a análise de conteúdo com a etapa de pré-análise. Naquele momento, foi realizada a leitura flutuante dos textos para conhecê-los melhor antes de submetê-los à exploração e codificação.

A exploração do material constitui, geralmente, uma fase longa e fastidiosa que tem como objetivo administrar sistematicamente as decisões tomadas na pré-análise. Refere-se fundamentalmente às tarefas de codificação, envolvendo: o recorte (escolha das unidades), a enumeração (escolha das regras de contagem) e a classificação (escolha de categoria) (GIL, 2008, p. 152).

A leitura flutuante ajudou-nos a "mergulhar" no sentido e significado dos textos selecionados. Após esse processo, uma nova leitura foi necessária para destacar as frases e parágrafos mais relevantes, codificando as unidades de registro, ou seja, identificando e registrando visualmente (com o marcador de texto digital do leitor PDF) quais princípios didático-pedagógicos estavam presentes nos textos. Anotações também foram feitas (com a ferramenta de comentários do leitor PDF) à margem dos parágrafosdestacados.

Após a codificação do material à luz das categorias e subcategorias anteriormente estabelecidas, foi realizado o tratamento e a interpretação dos dados (unidades de registro - palavras ou frases - unidades de contexto - os parágrafos que abrigam as unidades de registro) extraídos dos PPCs. É durante a fase de tratamento e interpretação que os dados ganham sentido e significado (Moraes, 1999). Segundo Gil (2008, p. 153),

o tratamento dos dados, a inferência e a interpretação, por fim, objetivam tornar os dados válidos e significativos. Para tanto são utilizados procedimentos estatísticos que possibilitam estabelecer quadros, diagramas e figuras que sintetizam e põem em relevo as informações obtidas.

Com base nesse trabalho, foi construído então um texto sobre cada PPC organizando nossas análises e interpretações a respeito dos dados obtidos em cada documento em função das categorias e subcategorias que orientaram nossa pesquisa. Também construímos um quadro indicando quantas unidades de registro referentes às abordagens e teorias de aprendizagem estavam presentes nos PPCs analisados. Os textos e o quadro são apresentados de forma resumida nos tópicos seguintes.

\section{Discutindo os dados}

Dos sete cursos de Pedagogia oferecidos na modalidade EaD pelas universidades federais da Região Nordeste, cinco tiveram seus PPCs analisados em nossa pesquisa; os dois documentos faltantes não nos 
foram fornecidos. No texto que segue, os nomes das cinco instituições participantes foram substituídos por letras (A, B, C e assim por diante), de modo que o PPC da instituição A será identificado pelo código PPCA, o da instituição $B$ pelo código PPCB e assim sucessivamente.

Desde já é útil informar que algumas dificuldades foram encontradas durante a realização da análise dos documentos. Em parte pela falta de padronização dos PPCs no que diz respeito à forma como comunicam os princípios e processos de ensino-aprendizagem defendidos pelas universidades para os cursos. O mesmo ocorre em relação aos critérios e instrumentos de avaliação. Outra dificuldade relaciona-se com o fato de que os princípios defendidos por algumas das teorias e abordagens descritas em nosso referencial teórico chegam aos PPCs de forma indireta, ou seja, por textos de terceiros que serviram de base para a elaboração da documentação, e não necessariamente por textos de autores diretamente filiados aos paradigmas. Isso torna mais difícil o processo de identificação da origem dos princípios didático-pedagógicos identificados nos PPCs. Podemos exemplificar tal dificuldade recorrendo aos diversos princípios escolanovistas presentes nos PPCs que surgem mesclados a um forte vocabulário freiriano. Por mais que tais princípios atendessem aos critérios que nos permitiam identificá-los com o paradigma escolanovista, a linguagem freiriana provocava certo ruído durante a análise. Realizamos, então, uma breve pesquisa paralela para identificar até que ponto os autores escolanovistas influenciaram o desenvolvimento da pedagogia freiriana, de maneira que pudéssemos identificar se, de fato, os princípios escolanovistas estavam ali presentes. Encontramos pelo menos três autores (Dermeval Saviani, Vanilda Paiva e Michel R. Mathews) que já haviam, antes de nós, percebido as semelhanças entre os princípios e identificado a influência de autores escolanovistas como John Dewey e CelestinFreinet no desenvolvimento da pedagogia de Freire ${ }^{2}$, o que nos deu maior segurança para confirmar a presença do Escolanovismo nos PPCS analisados.

\subsection{Análise de conteúdo do PPC da instituição A (PPCA)}

No PPCA percebe-se grande preocupação em enumerar e descrever ferramentas utilizadas durante o processo pedagógico do curso. Tal preocupação suplantou a discussão propriamente pedagógica, de maneira que pouco é dito sobre o uso de tais ferramentas. De toda forma, foi possível identificar leve presença de princípios escolanovistas e construtivistas no texto do documento. O Escolanovismo surge em trechos que incentivam o uso de atividades práticas integradas ao processo formativo, como a produção de recursos didáticos pelos estudantes ao longo do curso em laboratórios presenciais próprios para esse fim (mais tarde soubemos que tais laboratórios nunca foram montados); a recomendação de que seja aproveitada a vivência profissional dos estudantes que já atuam em sala de aula como um dos elementos desencadeadores do processo formativo da turma também sugere influência escolanovista. De fato, o PPCA defende que a experiência prática permeie toda a formação, evitando um processo pedagógico exclusivamente livresco.

No que tange ao Construtivismo, sua presença foi identificada em apenas um parágrafo, que se refere ao conflito sociocognitivopiagetiano proporcionado pelo uso do fórum virtual, ainda que o PPC não faça menção direta ao nome de Piaget. Sabemos que o conflito sociocognitivo é uma referência presente também em trabalhos de autores posteriores a Piaget. Na verdade, e como já foi dito, tivemos dificuldades em atribuir com precisão alguns dos princípios que identificamos nos textos aos autores estudados em nosso referencial teórico, pois na grande maioria das vezes não há citação direta (nem indireta) às fontes; em outras situações, os princípios chegam pelo trabalho de autores secundários, e mesmo esses nem sempre são citados. De fato, não são poucos os parágrafos nos quais os princípios simplesmente "aparecem" nos textos. Em tais situações, atribuímos tais princípios às teorias mais próximas presentes em nosso referencial teórico.

2 Para conhecer melhor a influência escolanovista no pensamento freiriano, consultar Torres (2002) e as obras sugeridas pela autora 
Para o documento, o fórum é o espaço que propicia a reflexão a respeito das próprias ideias frente às dos colegas e formadores, ajudando a depurar o próprio conhecimento. Como já foi dito, a ênfase do PPCA em descrever ferramentas disponíveis no ambiente suplanta a maior parte da discussão que deveria ser didático-pedagógica; assim, nada de muito relevante para nossa pesquisa foi encontrado a respeito dos processos e instrumentos de avaliação da aprendizagem, uma vez que interessava-nos identificar, nos textos, princípios relacionados às teorias de aprendizagem, princípios esses inexistentes nas descrições técnicas das ferramentas (chat, fóruns, questionários etc.) disponíveis no ambiente.

\subsection{Análise de conteúdo do PPC da instituição B (PPCB)}

O PPCB traz forte ênfase escolanovista, atribuindo grande importância ao uso da experiência de vida dos estudantes durante o processo formativo como recurso para tomada de consciência sobre a condição profissional: "a dimensão biográfica [...] recupera a trajetória de vida e de formação, possibilitando ao estudante-professor a tomada de consciência de seu processo de formação pessoal e profissional". A trajetória de vida e de formação deve ser recuperada durante o curso pela escrita de memórias e por sua articulação com os conteúdos das disciplinas, remetendo-nos ao princípio escolanovista que defende a articulação entre a experiência de vida fora da instituição de ensino com aquela que ocorre dentro da instituição ao longo da formação.

Também é perceptível a ênfase escolanovista no compromisso que o documento assume com uma epistemologia da prática, ou seja, uma formação baseada na vivência, na experiência, em vez de uma formação essencialmente teórica. O PPCB, em um discurso muito próximo ao aprender a aprender escolanovista, considera que a epistemologia da prática deve favorecer a ressignificação de aprendizagens (essência do aprender a aprender).

Foi identificada, ainda, alguma ênfase construtivista na defesa que o documento faz do uso do portfólio como recurso avaliativo. “Como instrumento de avaliação de aprendizagem, o portfolio oportuniza: o pensamento divergente; a valorização da capacidade de fazer perguntas; a reelaboração de conhecimentos e a criação pessoal". Segundo o PPCB, esse instrumento permite que o processo avaliativo seja permanente e auxilia o estudante a refinar seu próprio trabalho pelo também constante processo de reflexão sobre os erros e acertos durante a própria aprendizagem. Adicionalmente, os registros existentes no portfólio oportunizariam a avaliação do curso, uma vez que os estudantes seriam incentivados a considerar os pontos positivos e negativos da formação oferecida.

Em que pese a defesa feita pelo PPCB sobre o portfólio como instrumento de avaliação, além de referências diretas ao Construtivismo e ao Socioconstrutivismo, vale destacar que o próprio documento afirma que são previstas apenas duas avaliações obrigatórias e pontuais por disciplina (uma realizada no ambiente virtual e outra presencial em forma de prova escrita). O uso do portfólio seria facultativo, como instrumento adicional, e o PPCB não dá pistas sobre como seria feita essa integração.

\subsection{Análise de conteúdo do PPC da instituição C (PPCC)}

Os contornos da proposta pedagógica do PPCC indicam haver influências construtivistas e socioconstrutivistas. De fato, o documento declara-se construtivista, afirmando que esse paradigma de ensino-aprendizagem seria o mais adequado ao entendimento de formação defendido pela instituição. Adicionalmente, o PPCC considera que mais importante que as ferramentas tecnológicas são as pessoas envolvidas no processo pedagógico e o ambiente gerado pelo encontro dessas pessoas. Para o documento, "muito mais do que recorrendo à mediação tecnológica, é a relação humana, o encontro com o(s) outro(s) que possibilita ambiência de aprendizagem". Isso nos remete ao Socioconstrutivismo, bem como à consideração de que os estudantes devem compreender que todo conhecimento é produzido em um contexto social e histórico com o qual guarda relações. 
O documento ainda considera que os alunos são sujeitos que constroem e reconstroem seus conhecimentos (Construtivismo) e que ressignificam suas histórias pessoais a partir da experiência profissional (Escolanovismo). De fato, o PPCC defende que a experiência profissional dos estudantes seja incorporada ao processo pedagógico, de modo que o vivido seja pensado e o pensado seja vivido, articulando o desenvolvimento teórico das disciplinas com sua construção pela prática. Nada é informado sobre os processos e instrumentos de avaliação da aprendizagem.

\subsection{Análise de conteúdo do PPC da instituição D (PPCD)}

A influência escolanovista é identificada em diversos trechos do documento: na defesa da utilização do conhecimento obtido pela experiência pessoal e profissional dos estudantes como um dos recursos mais importantes ao longo do processo formativo e no compromisso com a aprendizagem baseada na prática da pesquisa (ensino com pesquisa) ao longo do curso: "A prática como componente curricular [...] ocorrerá desde o início do Curso, articulando-se de forma orgânica com as disciplinas teóricas".

Há uma compreensão construtivista a respeito do papel dos formadores, percebidos como instigadores da curiosidade, da motivação e do interesse de cada estudante, em vez de transmissores de conhecimentos;os formadores "cumprem o papel de facilitadores da aprendizagem, esclarecendo dúvidas, reforçando a aprendizagem, coletando informações sobre os estudantes para a equipe e, principalmente, na motivação". É defendido o fortalecimento da autonomia dos estudantes e da capacidade de autoavaliação. Por outro lado, há o reconhecimento sobre o caráter social da aprendizagem na defesa que o documento realiza de que se faça compreender que o conhecimento é social e culturalmente situado.

\subsection{Análise de conteúdo do PPC da instituição E (PPCE)}

Como nos demais documentos, há influência escolanovista na defesa da atividade prática e da experiência profissional como fios condutores do processo formativo e no ensino com pesquisa. Tal influência está presente ainda na defesa constante da autonomia do estudante (também cara ao Construtivismo) e do lema escolanovista "aprender a aprender": "Este aluno deve ser considerado como um sujeito do seu aprendizado, desenvolvendo autonomia e independência em relação ao professor, que o orienta no sentido do aprender a aprender e aprender a fazer".

É reconhecida, também, a dimensão social da aprendizagem quando o PPCE destaca a relevância do grupo social no qual o processo de ensino-aprendizagem ocorre e na defesa de considerar as situações em que deve haver a construção coletiva do conhecimento: “consideramos a característica de estudo autônomo da EaD; no entanto, acatamos a contribuição das teorias sobre aprendizagem que demonstram a eficácia da construção coletiva do conhecimento, da necessidade do grupo social como referência para o aprender". O Socioconstrutivismo surge, ainda, na oferta de tutoria presencial grupal, que deve estimular o trabalho coletivo, favorecendo o confronto de ideias e a formação de atitudes. No que diz respeito à avaliação da aprendizagem, pouco é informado. Fala-se em avaliação contínua, mas não é descrita sua operacionalização nem os instrumentos utilizados.

A seguir oferecemos um quadro que sintetiza a informação obtida pela análise de conteúdo dos PPCs. Para chegarmos aos números abaixo utilizamos análise de conteúdo, sem uso de software. O processo está detalhado no tópico referente à metodologia. 
Quadro 2: Números de unidades de registro relacionadas às teorias de aprendizagem identificadas em cada PPC

\begin{tabular}{|l|c|c|c|l|}
\hline \multirow{2}{*}{ PPCs } & \multicolumn{3}{|c|}{ Categorias } & \multirow{2}{*}{} \\
\hline PPCA & 3 & Construtivismo & Socioconstrutivismo & \\
\hline PPCB & 3 & 1 & 0 & $\begin{array}{l}\text { Números de unidades } \\
\text { de registro que reme- } \\
\text { tem a cada teoria por }\end{array}$ \\
\hline PPCC & 2 & 4 & 2 & PPC \\
\hline PPCD & 7 & 2 & 3 & \\
\hline PPCE & 7 & 1 & 3 & \\
\hline
\end{tabular}

Fonte: Costa e Silva, 2016, p. 181.

\section{Considerações finais}

Em todos os documentos analisados, percebemos a influência do Construtivismo e/ou do Socioconstrutivismo. Seja na defesa da autonomia do estudante durante a construção e reconstrução do conhecimento, seja na defesa do trabalho colaborativo e das aprendizagens social e culturalmente situadas. Tais achados não chegam a surpreender aqueles que conhecem a literatura educacional contemporânea sobre processos de ensino-aprendizagem. De fato, nossa hipótese era, precisamente, a de que tais influências seriam identificadas. Contudo, surpreende-nos perceber a herança escolanovista tão presente em todos os projetos pedagógicos, considerando que o ápice do Escolanovismo data de quase um século atrás.

Em que pesem as influências citadas, os documentos não são objetivos quanto à operacionalização dos princípios didático-pedagógicos defendidos no que tange ao desenvolvimento das tecnologias (ambientes, materiais e atividades) empregadas no curso. Os textos são predominantemente teóricos e muitas vezes omissos em aspectos importantes como a descrição dos processos pedagógicos, marcadamente dos processos e instrumentos avaliativos. Por um lado, a falta de detalhamento e objetividade dos textos pode ter a justificativa de garantir a autonomia dos professores nas escolhas de suas estratégias pedagógicas e dos recursos que desejam utilizar; por outro lado, isso impossibilita ao pesquisador identificar qual o compromisso didático-pedagógico abraçado pelo curso, bem como o nível de apropriação metodológica das teorias defendidas ao longo do documento.

\section{Referências}

Costa e Silva, A. A. (2016) Teorias de aprendizagem no design em tecnologia educacional dos cursos de pedagogia a distância. Dissertação de mestrado. Universidade Federal de Pernambuco.

Ghiraldelli Júnior, P. (2006)(p. 115). Filosofia da Educação. São Paulo: Ática.

Gil, A. C. (2008). Métodos e técnicas de pesquisa social (6 $6^{\text {th }}$ ed.,p. 200). São Paulo: Atlas.

Lerner, D. O ensino e o aprendizado escolar: argumentos contra uma falsa oposição. (2002). In: J. A. Castorina; E. Ferreiro; D. Lerner\& M. K. Oliveira. Piaget - Vygotsky: novas contribuições para o debate (pp. 18 - 42). São Paulo: Ática.

Moraes, R. (1999). Análise de conteúdo. Revista Educação, Porto Alegre, 22(37), 7-32.

Oliveira, M. K. (2002). Vygotsky: aprendizado e desenvolvimento, um processo sócio-histórico (4 ${ }^{\text {th }}$ ed.,p. 137). São Paulo: Scipione. 
Pilleti, C. \&Pilleti, N. (2012). História da Educação: de Confúcio a Paulo Freire (p. 286). São Paulo: Contexto.

Pritchard, A.; Woolard, J.(2010). Psychology for the classroom: constructivism and social learning (p. 415). Nova lorque: Routledge.

Racy, P. M. P. D. (2010). Psicologia da Educação: origem, contribuições, princípios e desdobramentos (p. 210). Curitiba: Ibpex.

Richmond, P. G. (1981). Piaget: teoria e prática (2 ${ }^{\text {th }}$ ed., p. 115). São Paulo: Ibrasa.

Sanches, R. C. F. (2009). Avaliação institucional. (p. 107). Curitiba: lesde Brasil.

Silva, R. C. (2011). Gestão do Ensino Superior: temas atuais (p. 223). São Paulo: Biblioteca24horas.

Simões, S. P. (2012). O projeto pedagógico institucional e projeto pedagógico do curso. Acesso em 04 de novembro de 2014. Disponível em: <http://ww.aedb.br/seget/artigos07/809_painel_do_simped.pdf>.

Torres, R. M. (2002). Educação Popular: um encontro com Paulo Freire (2 ${ }^{\text {th }}$ ed., p. 185). São Paulo: Loyola.

Veiga, C. G. (2007). História da Educação (p. 220). São Paulo: Ática. 